'to know what is better' for the patient in the medical respect, and my insistence needs to go no further than that. If ECT were the only choice for a moderately severely affected endogenous depressive, then I have found that their attitude to treatment is, 'Do something that makes me better.' Those more severely depressed than that really are past caring what one does. I have in any case, in an anecdotal though large experience, found that the continuance of antidepressives for only a week or two longer than the three weeks which was used as the trial period in the recent paper by Davidson et al (1977), the deludedly depressed do respond to antidepressives. One can argue about the relative merits of ECT and antidepressives in such cases, but there is still a choice.

\section{Highcroft Hospital,}

Erdington, Birmingham $B_{23} 6 A X$

\section{B. H. Fookes}

\section{Reference}

Davidson, J. R. T., McLeod, M. N., Kurland, A. A. \& White, Helen L. (I977) Antidepressant drug therapy in psychotic depression. British Journal of Psychiatry, 131, 493-6.

\section{Dear Sir,}

The College's Memorandum on the Use of Electroconvulsive Therapy quotes a paper by John Harris and myself in which 15 patients were treated with EGT and placebo tablets and 16 with 'pseudo ECT' and imipramine. The dose of imipramine was not stated in the paper, and Dr Farrant in a letter (1977) refers to this and 'insufficient data ... provided to substantiate the alleged differences between treatment groups. The original paper was a model of conciseness, and anyone wanting the fuller details has been supplied with them on request (see Barton, 1977). Imipramine was prescribed on a progressive dose schedule for the first seven days-10o $\mathrm{mg}$, I $00 \mathrm{mg}$, I $50 \mathrm{mg}, 200 \mathrm{mg}, 250 \mathrm{mg}, 300 \mathrm{mg}$, $300 \mathrm{mg}-$ thereafter the dose could be varied on clinical grounds.

The original paper contains a table with the results of treatment classified as 'marked', 'moderate', 'slight', and 'no improvement'. Ten of 14 ECT patients who completed the trial showed marked improvement, and only one of 12 imipramine patients who completed the trial is similarly categorized. Where the term 'significant' is used, this may be taken to imply $\mathrm{P}<\cdot 05>\cdot 0$. The withinpatient comparisons were made by the Wilcoxon Matched Pairs Sign Ranks Test (Siegel, I956). The between-treatment comparisons, in which 'ECT produced a significantly greater reduction in six symptoms-depressed mood, suicide, middle insomnia, agitation, psychic anxiety and loss of insight -while imipramine failed to show superiority in any symptom, used the Mann Whitney U-test (Siegel, 1956). While a Behaviour Rating Scale administered by nurses showed no differences between treatments, the paper did specifically comment on the crude nature of the scale.

The patients in this trial were diagnosed by two clinicians as suffering from depression and chosen for ECT assuming that imipramine was not available. At the same time, patients diagnosed as suffering from depression and not thought to require electroplexy were admitted to a trial of imipramine or placebo, with the same dose scheduled for imipramine (Robin and Langley, 1964).

A retrospective comparison of all patients chosen for the ECT trial with those for the conservative trial showed the former to have severe impairment of functional efficiency, heavy night sedation, day sedation required, severe degree of depression, suicidal preoccupations, genital symptoms, loss of insight, paranoid symptoms, more symptoms present; significantly more frequently than the patients in the conservative trial, who had diagnosis of neurotic depression, more than 6 admissions, no night sedation, initial insomnia.

The results of both trials may be combined in the table on p. 320 , which appears to show the marked superiority of ECT over imipramine in patients suitably selected, and poorer results of imipramine in those patients when compared with patients treated with the drug who were not thought to require ECT.

Runwell Hospital,

Ashley Robin

PO Box 3,

Wickford, Essex SSII $7 Q E$

\section{References}

BARton, J. L. (1977) ECT in depression: the evidence o controlled studies. Biological Psychiatry, 12, 687.

Farrant, W. (1977) British Journal of Psychiatry, 13r, 646.

RoBIN, A. \& HARris, J. A. (1962) A controlled comparison of imipramine and electroplexy. Fournal of Mental Science, 108, 217.

- \& LANGley, G. E. (1964) A controlled trial of imipramine. British Fournal of Psvchiatry, 110, 419.

Royal College of Psychiatrists (1977) Memorandum on the use of electroconvulsive therapy. British fournal of Psychiatry, r31, $26 \mathrm{r}$.

Siegel, S. (1956) Non-parametric Statistics. New York: McGraw-Hill. 